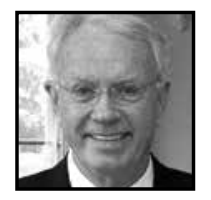

\title{
Commentary Are You Experienced?
}

\author{
William F. Pinar
}

\author{
$[T]$ eacher education, like education \\ itself, is a moral practice rather than a technological project. \\ -Anne Phelan (2011, p. 210)
}

\section{ABSTRACT}

Educational experience, I suggest, depends on having embodied experience from which one can learn. What can one learn from virtual experience? One can acquire information online, but can one craft that personal practical knowledge that derives from being experienced? That ongoing project requires that information be worked through-idiosyncratically-incorporating the new into one's prior knowledge and emotional-intellectual gestalt, thereby cultivating the capacity for (situation-specific) judgment. Despite policymakers' insistence that technology structure almost every classroom experience, many educators appreciate that their subjective presence is prerequisite to social learning. These facts and convictions inform this brief commentary on "experience."

\footnotetext{
oday's ongoing unquestioned demand for technology in education is justified as utilitarian-presumably preparing students and their teachers for an even more thoroughly technological future-even though the pace of technological change ensures that any such preparation must miss the mark. Never mind the facts, promises prevail, as promoters assure us that technology only improves student learning. Universities and schools seem powerless to resist, diverting funds from teachers and students to purchasing the products technology companies sell.
} 
Constantly acquiring technology has produced a "slick and fast-growing sales force," Matt Richtel (2011, p. A1) reports, hired by computer and other technology companies determined to profit from public financing. The technology bubble continues to inflate, Richtel (2011) continues, even as "questions persist about how effective hightech products can be at improving student achievement. The companies say their products engage students and prepare them for a digital future, while some academics say technology is not fulfilling its promise" (p. B7). ${ }^{2}$

Standardized examinations have long been a prominent instance of the technologization of education. Reducing educational experience to numbers misrepresents student achievement. In the standardization technologization enforces experience evaporates. Not only in teacher education does standardization eviscerate that educational experience from which professional judgment derives. Recognizing this risk, medical educators from the Mayo Clinic "specifically set out to teach against the test," Abigail Zuger (2014, p. D4) reports. Instead of standardized protocols, Zuger continues, these "educators took their students through complicated, contradictory cases for which there were no clear 'best' strategies, but many reasonably acceptable ones" (p. D4). Is not the same the case for teachers in actual school classrooms? Everyday experience comes with complexity that technologization cannot replicate or adequately anticipate; only flesh-and-blood educators face to face with students can negotiate the every-shifting situatedness of embodied learning in actual, not virtual, situations.

It is not just medical educators who recognize the risk to education that the standardization intrinsic to technologization poses. ${ }^{3}$ From Idaho to Illinois, schoolteachers have been in open revolt against the mindless installation of computers as the salvation of U.S. "school reform." In 2011 the Idaho state legislature passed a law that requires all high school students to take online classes to graduate, requiring them and their teachers to purchase laptops or tablets. To subsidize these mandatory expenditures, the state proposed to shift tens of millions of dollars away from the salaries of teachers and administrators, declaring that technology has repositioned teachers from the centers of classrooms to their sidelines, from where they become "more of a guide," assisting students to work through "lessons delivered on computers" (Richtel, 2012, pp. A1, B4). Teachers marched on the capital, charging that, "lawmakers [had] listened less to them than to heavy lobbying by technology companies, including Intel and Apple" (pp. A1, B4). With parents they gathered 75,000 verified signatures, more than needed, to put a referendum on the ballot that November, the passage of which did in fact overturn the law. 
Illinois educators also protested the onslaught against educational experience that technology represents. Striking Chicago teachers were not only alarmed by a new evaluation system and increasing class sizes but also, Monica Davey (2012) reported, by "data-driven education reform nationwide, which many perceived as being pushed by corporate interests and relying too heavily on standardized tests to measure student progress" (p. A14). Steve Parsons, a teacher at Lane Tech College, suspected Chicago wanted to move the curriculum online, effacing the primacy of teacher-student relationships in educational experience. Kelly Farrell, a kindergarten teacher at Higgins Elementary on Chicago's South Side, lamented that her class had become so large that she could not attend to each child. "They are 5 years old," she said. "They want their teacher's attention, and there is one of me and 43 of them" (quoted in Davey, 2012, p. A14).

Long before humanity began staring at screens and no longer at each other, the technologization of education had standardized not only the educational experience of students but also pedagogical practices, confining them to "best practices" that are, allegedly, "data-driven" and "evidence-based." Not only the curriculum but also teacher-student relationships risk becoming means to ends, not ends in themselves, relationships that can be central to the formation of youth struggling to learn what at first they might fail to understand. Relationships between teachers and students are intrinsically important, extensions and revisions of relationships between children and significant others, especially parents and caretakers. The educational experience of children, then, occurs within relationships to authority, embodied in actual persons emotionally engaged with each other.

"Whereas contemporary liberalism has come to consider 'authority' almost entirely in terms of the rule that binds citizens and government," Nancy Luxon (2013) points out, the classical liberals-she cites Locke, Rousseau, Kant-appreciated that "formative, personal relationships of authority prepare citizens to occupy common public spaces organized through words and deed" (p. 19). The education of children was "premised," Luxon continues, on "personal relationships to authority," including "parents" and "teachers," providing experiences of authority "that prepared individuals to exercise their liberty as citizens" (p. 19). Liberty and authority, she concludes, are paradoxically entangled, and, she adds, "that entanglement is one to be continuously and actively negotiated rather than one to be stabilized onto the dichotomous terms of hierarchy" (p. 19). A computer or tablet screen cannot substitute for the embodied actuality of negotiated relationships with actually existing educators committed to helping children learn from their lived experience, learning not necessarily linked to outcomes 
but enacting the paradox - the ongoing educational experiment—of affirming liberty within relationships of authority.

Educational experience is not without risk. The English word "experience," Martin Jay (2005) reminds us, is derived most directly from the Latin experientia, which denoted "trial, proof, or experiment" (p. 10). Insofar as "to try" (experei) contains the same root as periculum, or "danger," he notes, "there is also a covert association between experience and peril, which suggests that it comes from having survived risks and learned something from the encounter (ex meaning a coming forth from)" (p. 10). Academic study is not shopping, students are not customers and teachers are not service providers: market metaphors for educational thinking fool parents and politicians into fantasizing a problem-free path when not only etymologically but also experientially learning is sometimes uncomfortable, at least when it invites us to exceed what we already know and can think.

Standardization fools a gullible public into thinking that educational experience is everywhere the same. As Jay (2005) also mentions, the concept of experience is associated with "specific [rather] than general matters, with particulars rather than universals" (p. 10). Educational experience occurs within the two domains, the universal through the particular and vice versa; it is allegorical. ${ }^{4}$ As Colin Koopman (2009) points out, "the democratic contribution is thoroughly personal. This means that it is simultaneously individual and social just insofar as all persons find themselves simultaneously individuating from and associating with other persons" (p. 24). ${ }^{5}$ The social experience of learning with and from each other in classrooms small enough to encourage subjective presence in dialogical encounter-complicated conversation guided by erudite, engaging teachers 6 -institutionalizes opportunities for improvisation, discovery, and understanding.

Despite its intense technologization, Montaigne might recognize the present we inhabit. After all, he saw his own age as one of "corruption, violence, and hypocrisy," an assessment, Martin and Barresi (2006) explain, that forced him "to question what his age took to be knowledge, then the possibility of knowing altogether, and finally even the human capacity to seek truth consistently... [He] helped reorient modern philosophy from the external world and toward subjective experience" (p. 121). It is subjective experience that is eviscerated by staring at screens. While hardly guaranteed by the embodied presence of another, it can be encouraged by the subjectively present teacher unafraid of engaging emotionally as well as intellectually in conversation with those in her or his charge. Professionalization does not mean bureaucratization 
but subjective presence and the exercise of professional-ethical-judgment, as the epigraph underlines.

Educational experience is not experience in general. There can be no experience that does not belong to someone, a person, a human subject coming of age, coming to form, through the study of subjects. In this era of the "post"7, we assume there is no preexisting or "substantial self but something more intimately connected with experience" (p. 174). ${ }^{8}$ As crucial as "experience" is-when it is lived, embodied, subjectively undergone-it is not, Koopman (2009) underscores, "a foundation for knowledge, morality, or politics." (p. 8). ${ }^{9}$ Indeed, experience can be misleading, as Juliet Mitchell (1975) knew, informed as it is by (patriarchal) culture, (unjust) circumstance, and an opaque historical moment. As Jay (2005) notes, Mitchell's "skepticism abut experiential self-evidence and her insistence on its mediation by more theoretical models of explanation" cautioned not only feminists but also others whose work rested on "the authority of subjective experience, either in the present or past" (p. 246). Indeed, experience-if it is to be educational-is to be learned from, not accepted at face value. It is the beginning not the end, but without actual educators authorizing such experience, conformity, not skepticism, seems the more likely outcome. "Conformity is the enemy of learning," Michael S. Roth (2014) points out, "because in order to conform you restrict our capacity for experience; you constrict our plasticity" (p. 168)..$^{10}$ If experience means anything at all, Jay (2005) concludes, "it involves an openness to the world" (p. 408). That is the cosmopolitan cause of curriculum as complicated conversation, a cause to which educational experience enlists our allegiance. As Phelan reminds us, teacher education, like education itself, is not a technological project. It is a moral one.

\section{Notes}

1. Richtel reported in 2011 that "billions" of dollars are at stake. In 2013, Singer (2014) reports, "sales of education technology software for pre-kindergarten through 12th grade reached an estimated $\$ 7.9$ billion, according to the Software and Information Industry Association" (p. B6).

2. Failing to fulfill its promise may be only the beginning of the problems the technologization of education poses, as research documents the deleterious consequences of substituting virtual for actual embodied experience (see Pinar, 2012, pp. 140-161). 
3. While too many educators have been hoodwinked into believing the hype, more than a few notice a difference between virtual and actual experience. "Several teachers," Hollander (2012) reported, "said their experience online has influenced their in-person classes - sometimes in counterintuitive ways" (p. A3). Ms. Emily McCarren, a Spanish teacher at Punahou School in Hawaii, told Hollander: "Maybe the takeaway has been really valuing time that you have with students," said. "When I have all 18 of my students in a classroom it's such a gift" (quoted in Hollander, 2012, p. A3).

4. In this general sense, allegory is a specific narrative that hints at a more general significance; see Pinar, 2012, p. 50.

5. He is here threading U.S. pragmatism through Emerson, James, and Dewey.

6. No standardized set of "practices" but individuated and situation-specific enactments of ideals.

7. We are now, we are told, post-human; see, for example, Agathocleous, 2011, p. 184.

8. Here Martin and Barresi are discussing Kant.

9. Koopman is here discussing Rorty.

10. Apparently even intellectual capacity, as measured by one's IQ score, "may be more malleable than previously believed - and more susceptible to outside influences, such as tutoring or neglect," according to findings by researchers at University College London, reported online in Nature (see Hotz, 2011, p. A3).

\section{References}

Agathocleous, T. (2011). Urban realism and the cosmopolitan imagination in the nineteenth century. Visible city, invisible world. Cambridge: Cambridge University Press.

Davey, M. (2012). Teachers' strike in Chicago roils families' lives. Union battles mayor. Complaints over pay, benefits, class size, and respect. The New York Times, Vol. CLXI, No. 55, $891, \mathrm{A1}, \mathrm{A} 14$.
Hollander, S. (2012). Online holdouts no more. Private schools in U.S. and abroad offer webbased classes through new venture. The Wall Street Journal, Vol. CCLX, No. 73, A3.

Hotz, R. L. (2011). As brain changes, so can IQ. Study finds teens' intellects may be more malleable than previously thought. The Wall Street Journal, Vol. CCLVIII (No. 894), A3. 
Jay, M. (2005). Songs of experience: Modern American and European variations on a universal theme. Berkeley: University of California Press.

Koopman, C. (2009). Pragmatism as transition: Historicity and hope in James, Dewey, and Rorty. New York: Columbia University Press.

Luxon, N. (2013). Crisis of authority: Politics, trust, and truth-telling in Freud and Foucault. Cambridge: Cambridge University Press.

Martin, R., \& Barresi, J. (2006). The rise and fall of soul and self. An intellectual history of personal identity. New York: Columbia University Press.

Mitchell, J. (1975). Psychoanalysis and feminism. Freud, Reich, Laing and Women. New York: Vintage-Random House.

Phelan, A. M. (2011). Towards a complicated conversation: Teacher education and the curriculum turn. Pedagogy, Culture \& Society, 19(2), 207-220.
Pinar, W. F. (2012). What is curriculum theory? [Second edition.]. New York: Routledge.

Richtel, M. (2011). Silicon Valley wows education, and woos them. The New York Times, Vol. $\operatorname{CLXI}(55,580), A 1, B 7$.

Richtel, M. (2012). Teachers resist high-tech push in Idaho schools. The New York Times, Vol. $\operatorname{CLXI}(55,640), A 1, B 4$.

Roth, M. S. (2014). Beyond the university. Why liberal education matters. New Haven, CT: Yale University Press.

Singer, N. (2014). September 15 . With tech taking over in schools, worries rise. The New York Times, CLXIII, No. 56, 625, B1, B6.

Zuger, A., M.D. (2014). February 11. The real world is not an exam. The New York Times, CLXIII, No. 56, 409, D4.

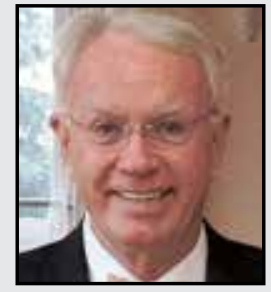

William F. Pinar is Professor and Canada Research Chair at the University of British Columbia. He has also served as the St. Bernard Parish Alumni Endowed Professor at Louisiana State University, the Frank Talbott Professor at the University of Virginia, and the A. Lindsay O'Connor Professor of American Institutions at Colgate University. The former President of the International Association for the Advancement of Curriculum Studies and the founder of its U.S. affiliate, the American Association for the Advancement of Curriculum Studies, Pinar is the author of Educational Experience as Lived: Knowledge, History, Alterity (Routledge, 2015). 